\section{ECCOMAS}

Proceedia
COMPDYN 2021

$8^{\text {th }}$ ECCOMAS Thematic Conference on Computational Methods in Structural Dynamics and Earthquake Engineering

M. Papadrakakis, M. Fragiadakis (eds.)

\title{
SEISMIC PERFORMANCE OF PAKISTANI-TECHNIQUE INFILLED REINFORCED CONCRETE FRAMES
}

\author{
Nisar Ali Khan ${ }^{1 *}$, Alessandro Vittorio Bergami ${ }^{2}$, Camillo Nuti ${ }^{3}$, Giorgio Monti ${ }^{4}$, Marco \\ Vailati $^{5}$ and Bruno Briseghella ${ }^{6}$ \\ 1,2,3 Department of Architecture, University Roma Tre, Rome, Italy \\ E-mail: \{nisarali.khan; alessandro.bergami; camillo.nuti \}@uniroma3.it, \\ ${ }^{4}$ Department of Structural and Geotechnical Engineering, Sapienza University of Rome, Italy, \\ E-mail: giorgio.monti@uniroma1.it \\ ${ }^{5}$ Department of Civil, Construction-Architectural \\ and Environmental Engineering, University of L'Aquila, Italy \\ E-mail: marco.vailati@univaq.it \\ ${ }^{6}$ College of Civil Engineering, Fuzhou University, China, \\ E-ma1l: bruno@fzu.edu.cn \\ ${ }^{*}$ Corresponding author: nisarali.khan@uniroma3.it
}

\begin{abstract}
Infilled reinforce concrete (IRC) frames are commonly built across the world. Modern building codes address the influence of infill walls in seismic design and assessment of existing structures. Other building codes commonly consider infill walls as non-structural elements and do not require any explicit verification. One of such codes is the Pakistan Building Code (PBC), which does not foresee recommendations and guidelines for IRC frame structures, despite being a common construction typology in the Country. Records of past earthquakes show that infill types and material properties strongly affect the seismic response of buildings thus highlighting the importance of such parameters and making the topic worth investigating in detail.

This paper introduces a numerical model for infill walls, which predicts different features of the nonlinear response, such as cracking, peak force, failure and residual force. Such features are expressed as function of infill friction coefficient between mortar and brick surface and mortar strength, whose effects are commonly neglected in available numerical models. The model is applied to a comprehensive case study of a three-story IRC frame factory building, located in the city of Mirpur, Pakistan, hit by an earthquake of magnitude 5.9 on 24 September 2019. The results obtained the model show good agreement with the observed in-situ damage patterns, thus revealing the importance of correctly modeling the infill walls when seismically designing and assessing Pakistani IRC buildings.
\end{abstract}

Keywords: Masonry infill wall, Nonlinear analysis, Diagonal strut model, Non-structural element, Infilled Reinforced Concrete (IRC) frame structures. 


\section{INTRODUCTION}

The construction typology of infilled reinforced concrete (IRC) frames is not only common in Pakistan but across the globe. The typology became more common in Pakistan especially after October 2005 Kashmir earthquake [1], [2], [3], [4], [5]. With the increasing demand for IRC frame constructions in the country, the local research community and practitioners started developing an increasing interest towards several important issues, such as, frame-infill interaction models, role of brick types, and optimal material properties of the infill wall constituents [6]. While the use of IRC frames has been growing in the Country, the Pakistan building code (PBC) has not developed any recommendation or guideline for their design and construction [1], [7]. This is also the case of many building codes around the world [8], [9], whereas some more advanced building codes, including Eurocode, already include some essential yet incomplete considerations about the role of infill walls in both design and assessment of IRC frame structures. As a matter of fact, many practitioners still consider infill walls as non-structural elements, despite being aware of their strong influence on the seismic response of IRC frame structures [10], [11]. This is also due to the fact that, although extensive studies have been dealing with the topic in the past 50 years, sound and reliable design and assessment methods including the effects of infills seem still far from being used in practice [12]. Besides, there is a lack of basic understanding regarding the infill walls contribution to the IRC frame response, whether it is beneficial or detrimental and under which circumstances. This depends on various parameters, such as: infills-frame interaction, infills-frame relative strength and stiffness, type of materials used for bricks, mortar and concrete [13][14][9]. Assessment of seismic performance of IRC frames requires proper modeling techniques and reliable analytical equations to correctly predict their response [15]. Many existing IRC frames are more vulnerable to seismic actions as a result of improper and poor understanding of such features [16].

Some usually neglected parameters, such as friction coefficient between mortar and brick surface, mortar strength, and their effects on the seismic performance of IRC frames are not reported in the literature, despite their strong influence on the failure mode of infill walls [17]. Recent earthquakes show that also newly built IRC frames designed with seismic detailing are equally vulnerable as older ones, due to the detrimental interaction with infills [18]. Moreover, IRC frames are not only vulnerable during natural seismic events, but also due to human-made hazardous events, such as blast and terrorism acts, which makes the topic worth investigating [19].

In case infill walls are uniformly distributed in plane and elevation of the building, IRC frames under seismic action are less vulnerable than the equivalent bare frames, because the infill walls interact directly with the surrounding RC frame [20]. However, brittle failures may occur in columns, beams and joints, due to local interaction. These issues should be dealt with when modeling an existing building [21].

The infill walls can be modeled by different numerical approaches, such as micro, meso, and macro modeling [22]. The former two require detailed computational efforts and are commonly used for detailed research purposes, while the latter makes use of one or more diagonal struts, which require less computational effort and are preferred in practical applications [23].

Usually, in Pakistan, common practice with IRC frames only accounts for infill walls through their dead load [2], [7]. As a consequence of such design practice, the same types of infill walls made of fire burnt clay bricks are used across the northern part, including Punjab, Khyber Pakhtunkhwa, Pakistan-administrated Kashmir, Baluchistan, capital territory Islamabad, and other seismic prone regions of the country, without the necessary variations in size and properties required by the local seismic hazard [24]. Besides, there are no variations in thickness or infill 
types related to the occupancy/types of the building, i.e., hospital, school, industrial, or residential, which is not a reasonable strategy for the seismic safety of those buildings [2], [1].

\section{NUMERICAL MODELLING}

Satisfactory advancements in modeling infill walls have been recently achieved in terms of simplified macro modeling, in which the infill panel is replaced by equivalent diagonal single or multiple struts. The laying of bricks and the materials mechanical characteristics affect the ability of such models to predict the local response and the damage pattern. In terms of global response, it has been widely recognized that the modeling choices of infill walls affect the overall seismic performance of IRC frame structures and bring to largely different outcomes.

Generally, seismic forces affect infill walls both in-plane and out-of-plane. In-plane interaction has been the object of several experimental researches, which concluded that infill panels behave as a monolithic resisting system, until partially detached from the surrounding frame and start behaving as a compression strut, which claims for adequate modeling. The proposed model focusses on this aspect.

Considering the construction typology of IRC frames in Pakistan, the materials used, and the common design practice, is the objective of the proposed numerical model, which is a modified version of Combescure (1996) [25] model expressed as function of friction coefficient between mortar and brick surface and mortar strength. It considers a compression diagonal strut representing the infill wall in the in-plane, with a simple yet effective constitutive law shown in figure 1 .

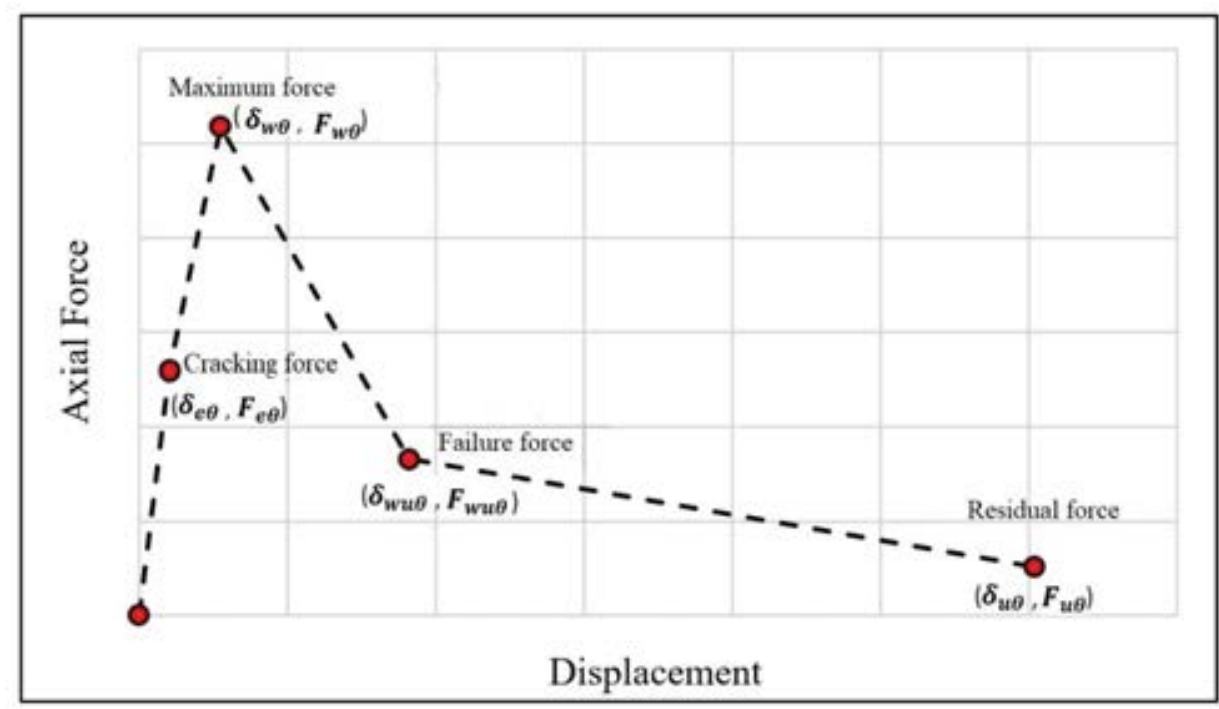

Figure 1. Adopted model for infill walls showing the main features of the response

The proposed model aims at better capturing such response at different stages, i.e., elastic, cracking, maximum force, failure, and residual force.

The relative stiffness between infill wall and column can be calculated by the dimensionless parameter first proposed by Stafford Smith (1967).

$$
\lambda_{h}=h_{c}\left[\frac{E_{m} \cdot t_{w} \cdot \sin 2 \theta}{4 E_{c} \cdot I_{c} \cdot h_{w}}\right]^{1 / 4}
$$


where $h_{c}$ is the height of the RC frame to the centerline of the beam, $E_{m}, E_{c}$ are the moduli of elasticity of masonry and concrete respectively, $t_{w}, h_{w}$ are the thickness and height of the infill wall, respectively, $I_{C}$ is the moment of inertia of the column, $\theta$ is the angle of the diagonal panel strut.

Many authors proposed different formulations for the diagonal panel strut width[22]. According to Mainstone (1974), it can be calculated by the following equation:

$$
\frac{w_{w}}{d_{w}}=0.17 \lambda_{h}^{-0.4}
$$

Where $w_{w}, d_{w}$ are width and inclined length of the diagonal strut.

The four branches, i.e., cracking, maximum force, failure, and residual force shown in figure 1, are described sequentially by the following equations.

It is expedient to start from the maximum force and the corresponding displacement:

$$
\begin{aligned}
& F_{w \theta}=f_{w} \cdot t_{w} \cdot w_{w} \\
& \delta_{w \theta}=\frac{f_{w}}{E_{w \theta}} d_{w}
\end{aligned}
$$

where, $f_{w}, t_{w}$ and $w_{w}$ are the compression strength of the wall along the diagonal direction, the wall thickness, and the strut width, respectively, and $E_{w \theta}$ is the elastic modulus along the diagonal direction at angle $\theta$, given by the following equation [26]:

$$
E_{w \theta}=\left[\frac{\cos ^{4} \theta}{E_{m h}}+\frac{\sin ^{4} \theta}{E_{m v}}+\cos ^{2} \theta \sin ^{2} \theta\left(\frac{1}{G}-2 \frac{v}{E_{m h}}\right)\right]^{-1}
$$

Where $E_{m h}, E_{m v}$ are the horizontal and vertical elastic moduli of masonry walls, respectively, $G$ is the masonry shear modulus, and $v$ is the Poisson ratio.

The cracking force of the infill and the corresponding displacement at the onset of the first branch of figure 1 , can be found as:

$$
\begin{aligned}
& F_{e \theta}=\frac{F_{w \theta}}{2} \\
& \delta_{e \theta}=\frac{F_{e \theta}}{2 K_{w \theta}}
\end{aligned}
$$

Where $K_{w \theta}$ is the diagonal strut axial stiffness, calculated as:

$$
K_{w \theta}=\frac{E_{w \theta} t_{w} w_{w}}{d_{w}} \cos ^{2} \theta
$$

Where $\theta$ is the strut angle.

The failure force and the corresponding displacement at the end of the third branch of figure 1 can be found as:

$$
\begin{aligned}
& F_{W u \theta}=\mu\left(f_{m} t_{w} w_{w}\right) \\
& \delta_{w u \theta}=0.005 \frac{h_{w}}{\cos \theta}
\end{aligned}
$$


Where, $\mu, f_{m}, t_{w}$, and $w_{w}$ are friction coefficient between mortar and brick surface, mortar compressive strength, wall thickness, strut width, respectively, and $h_{w}$ is the infill wall height.

Finally, the last point of residual force is proposed as:

$$
\begin{aligned}
& F_{u \theta}=\frac{F_{w \theta}}{10} \\
& \delta_{u \theta}=18 \delta_{w \theta}
\end{aligned}
$$

Having calibrated the strut model, in the following section it is applied in the comprehensive modeling of an infilled frame reinforced concrete building, selected as a case study.

\section{CASE STUDY}

The selected case study considers an IRC three-story factory building situated in Mirpur city, Pakistan, which was severely hit by the earthquake on 24 September 2019. The factory building is $17.7 \mathrm{~km}$ away from the epicenter. The model of the building and a satellite image are shown in figure 2. According to the acquired information, the building was designed in 1986, when the code did not enforce any seismic provisions. As per common practice in the country, infill walls were considered as non-structural components.
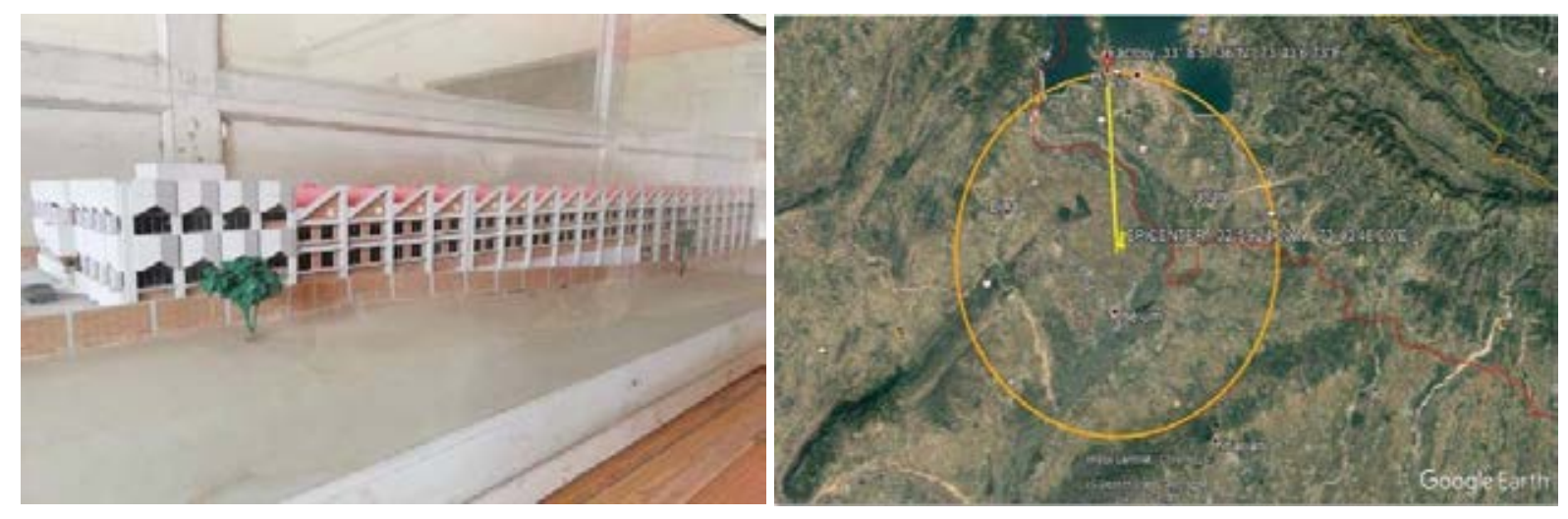

Figure 2. Model of the selected factory building (left) and satellite image location of the building from the epicenter (right)

According to the detailed site visits and survey reports of the building, some cracks were observed in the beams, columns and their joints whereas the infill walls are badly damaged, as shown in figures 3-6.

The overall in-plane dimensions of the building are $94.91 \mathrm{~m} \times 24.38 \mathrm{~m}$ and the typical interstorey height is $3.66 \mathrm{~m}$. It consists of three blocks, i.e., storage, manufacturing, and office at the back, center, and front, respectively. The infill walls are $228 \mathrm{~mm}$ (9 inches) thick made of solid fire burnt clay bricks. The geometry of beams and columns are rectangular with variable sizes depending on their location and ranging from $228 \mathrm{~mm} \times 457 \mathrm{~mm}$ to $228 \mathrm{~mm} \times 2438 \mathrm{~mm}$ and $305 \mathrm{~mm}$ x $305 \mathrm{~mm}$ to a maximum of $381 \mathrm{~mm}$ x $381 \mathrm{~mm}$. 

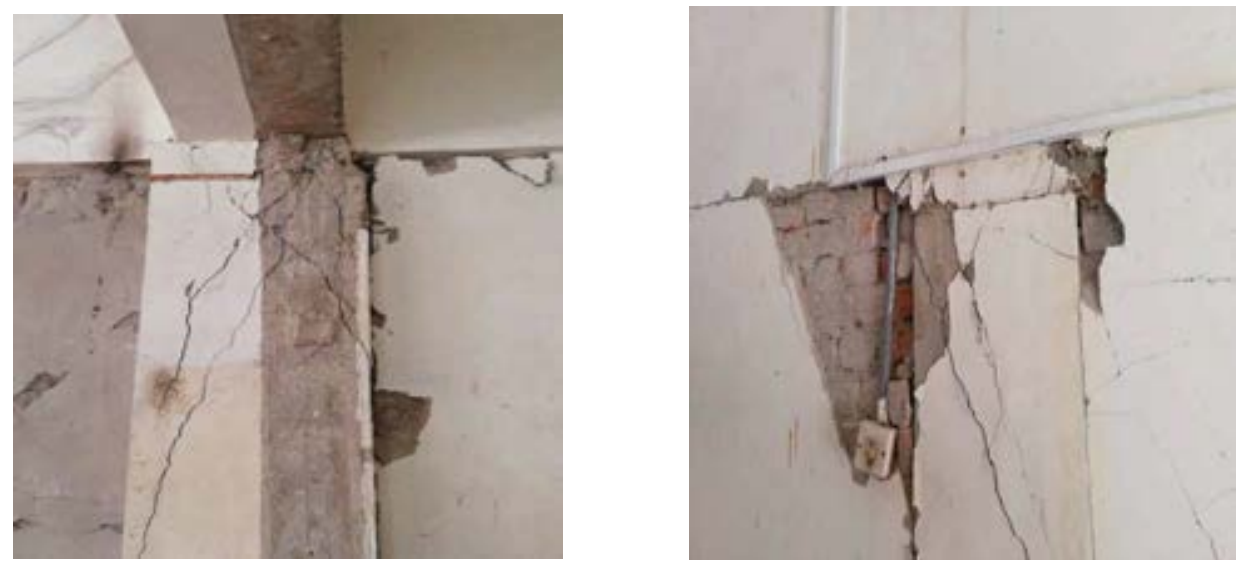

Figure 3. Cracks observed in beam (left), and column (right)
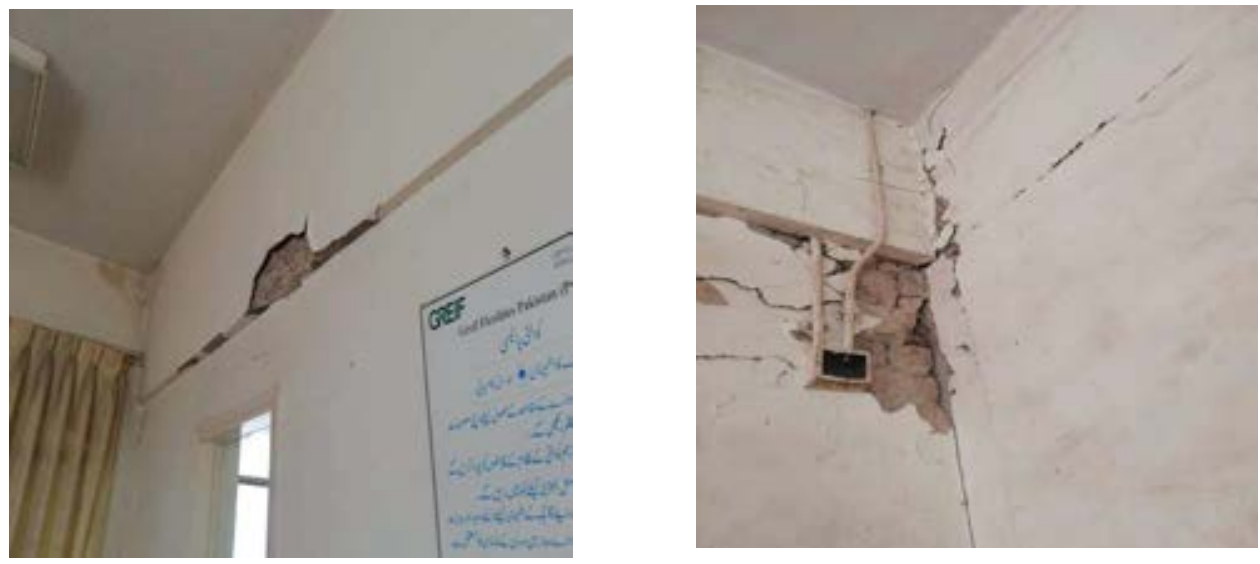

Figure 4. Cracks observed in column and infill (left), and joints (right)
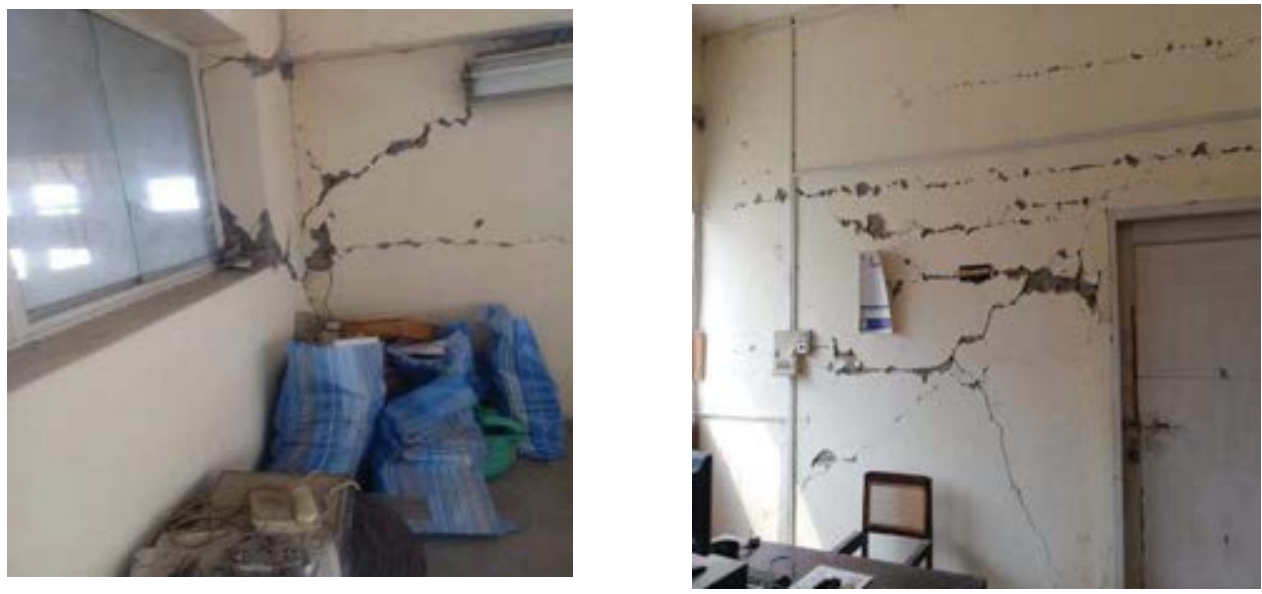

Figure 5. Cracks and damages observed in the infill walls in different parts of the building 

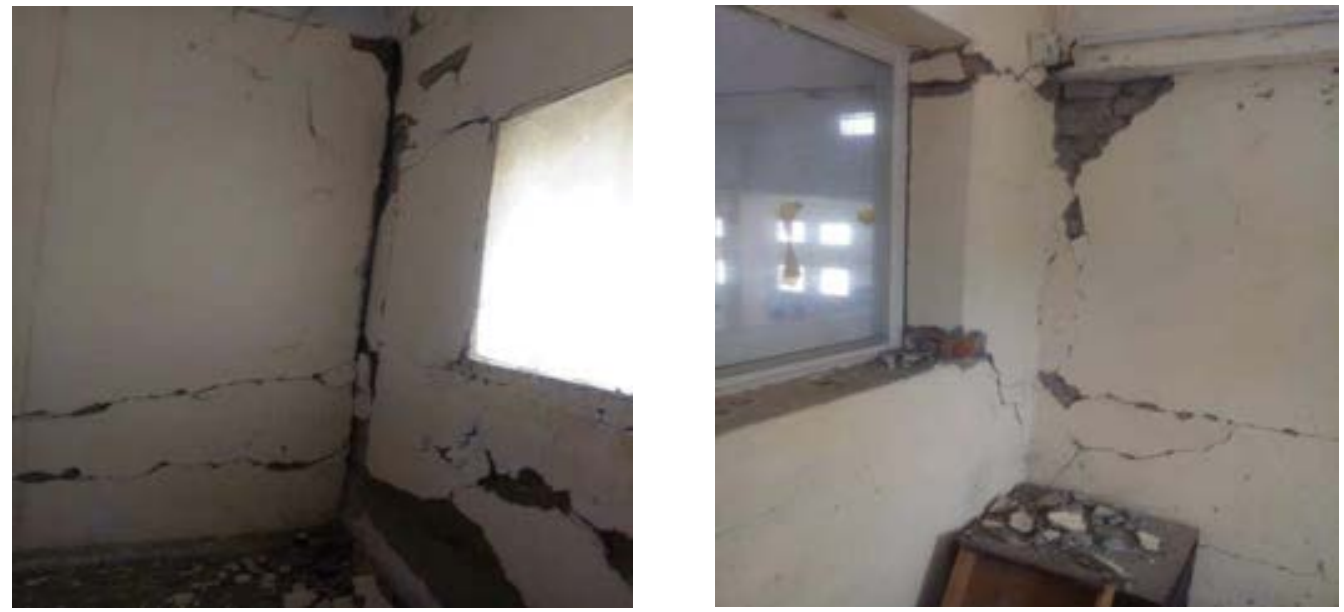

Figure 6. Cracks in column due to the presence of opening in infill (right) severe cracks in infill on the frame selected for analysis (left)

\section{NUMERICAL MODELS}

A 2-D frame is considered, pertaining to the office block where maximum damages in the infill walls were observed. Nonlinear static pushover analysis was performed considering two configurations: bare frame (BF) as reference, and infilled frame (IF). The foundation plan, the elevation of the selected frame having five equal bays of length $4.88 \mathrm{~m}$, equal inter-story height of $3.66 \mathrm{~m}$ and the geometry of beams and columns are shown in figures 7-9.

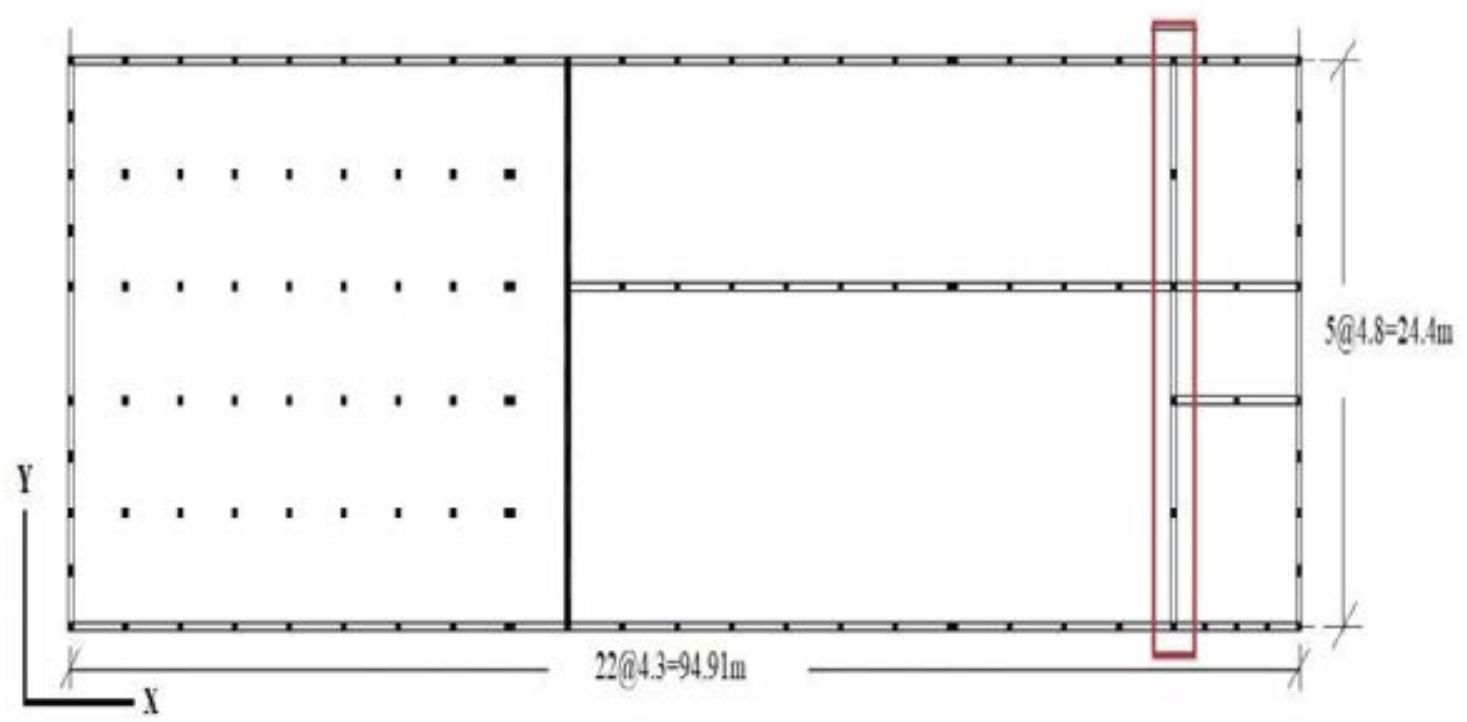

Figure 7. Foundation plan of the building and, highlighted, the frame selected for analysis 

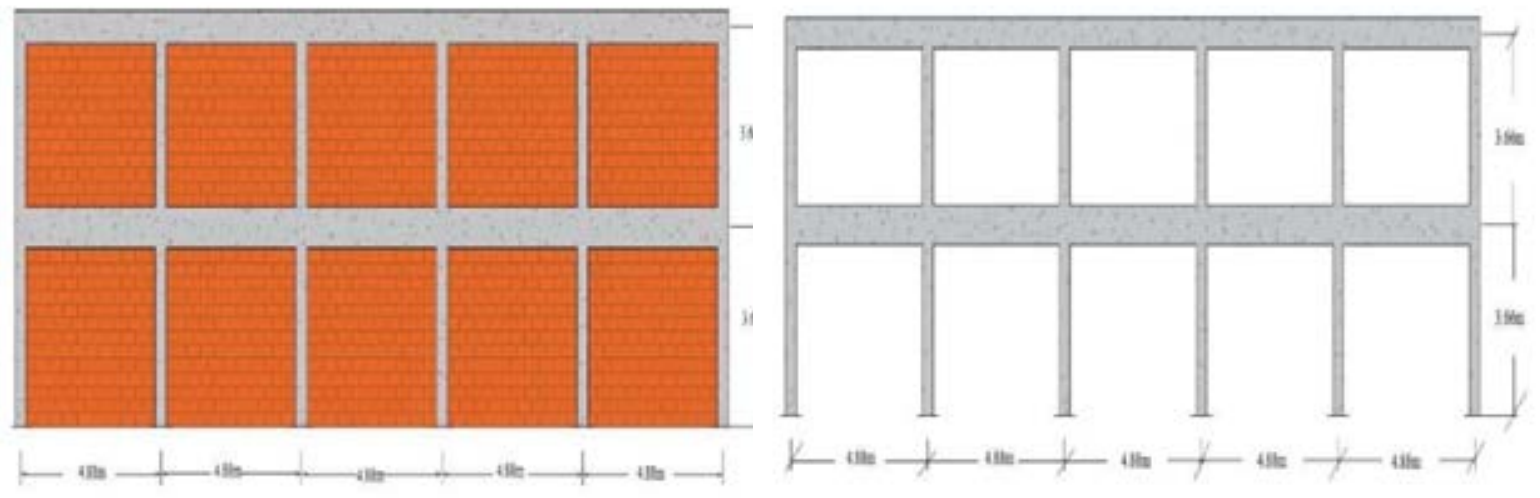

Figure 8. Frame selected for analyzing the infills (left), bare frame (right)
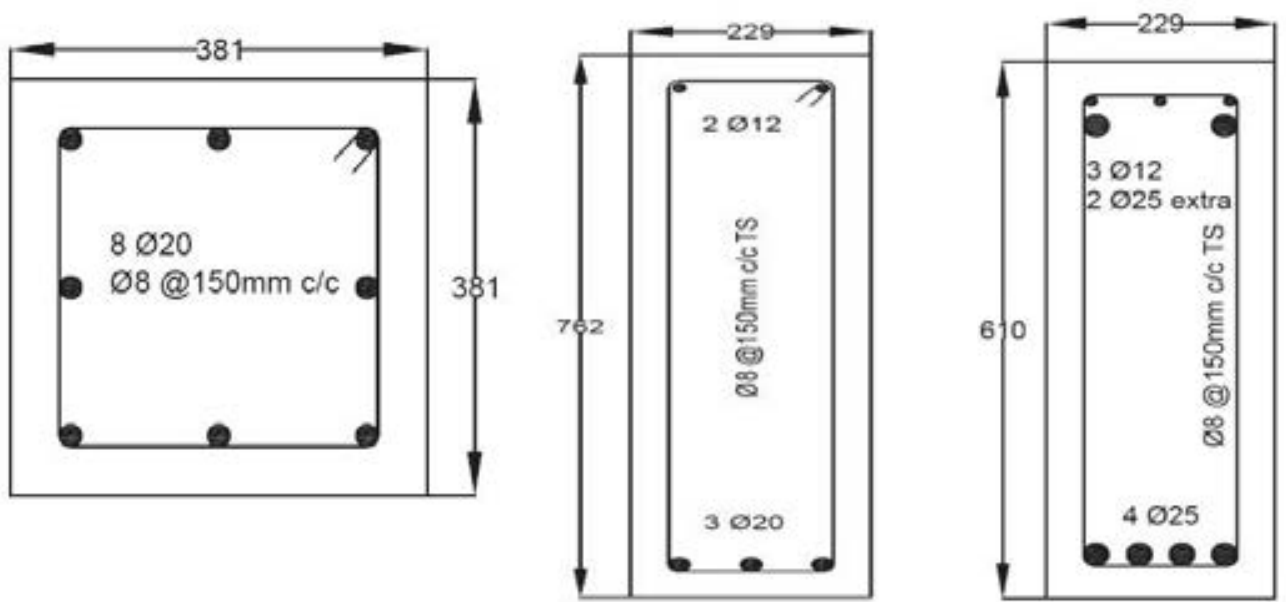

Figure 9. Section of columns (left), first-floor beam (center), second-floor beam (right)

The frame was modeled in SAP2000 where frame elements were used for beam-column elements and nonlinear multilinear elastic link with the proposed model properties were used for the infills. Mander (1988) [27]model was used for confined and unconfined concrete within the cross sections of the structural elements. From the available drawings and design specifications of the building, the characteristic values of compressive strength of the brick unit, brick masonry, mortar, concrete, and yield strength of steel are set as $8 \mathrm{MPa}, 4.3 \mathrm{MPa}, 5 \mathrm{MPa}, 20 \mathrm{MPa}$, and $400 \mathrm{MPa}$, respectively, which are commonly used properties in the country [2], [1], [24], [28], [29]. Other materials properties, such as friction coefficient between mortar and brick surface, and Poisson ratio are considered as 0.3 and 0.14 , respectively. The models of IF and $\mathrm{BF}$ are shown in figure 10. 

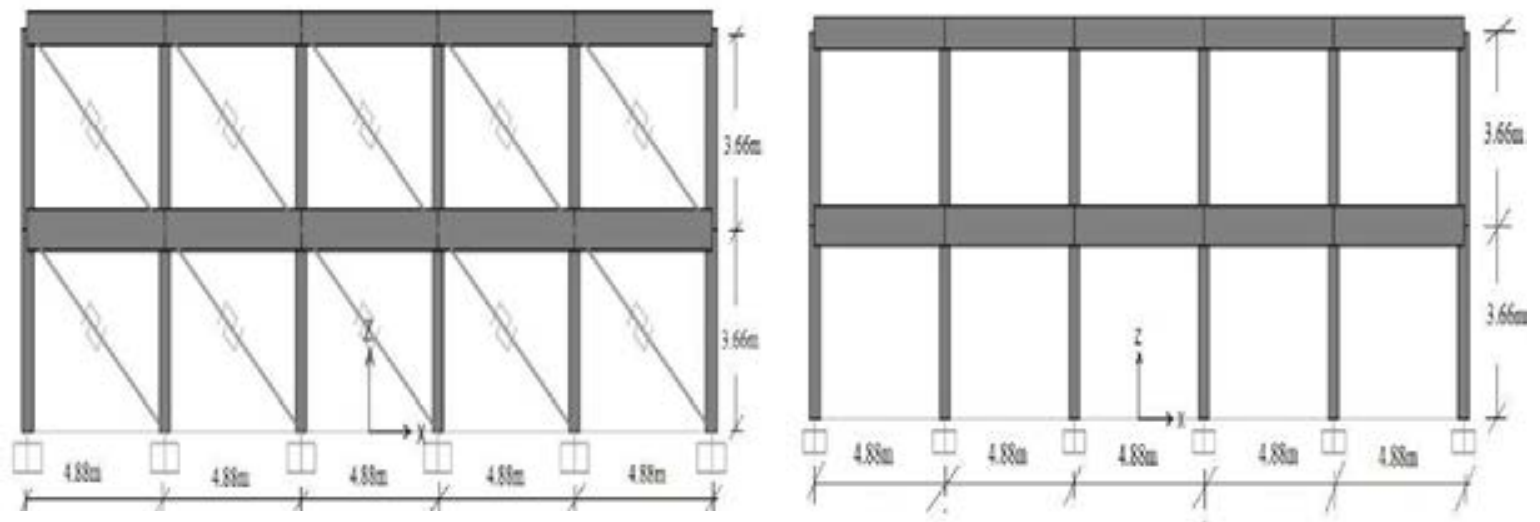

Figure 10. Models considering different configurations: infilled frame (left) bare frame (right)

\section{RESULTS AND COMPARISON WITH IN-SITU OBSERVED DAMAGE}

Detail surveys and site inspections of the building after the earthquake showed that the RC elements were not significantly damaged by the earthquake action. As shown in the figures 36 , some beams and columns were partially damaged, however, most of the damages were observed in the infill walls. In fact, they sustained a large portion of the horizontal forces and, consequently, increased significantly the stiffness and strength of the building, thus preventing the structural components from failing. In this case, the presence of the infills was beneficial to the overall performance of the structural elements. The BF model predicted much higher damage in the structural elements, while the IF model, thanks to the inclusion of the proposed struts, showed good agreement with the observed damage in the structure.

From the quantitative standpoint, the resulting capacity curves of IF and BF can be appreciated in figure 11. It is noticed that IF has an almost 3 times larger strength than BF, provided by the presence of the infills. Also, the initial stiffness increased 11 times, which resulted in a $70 \%$ decrease of the fundamental vibration period. It was also observed that drift ratio, top story drift, and ductility of IF compared to BF decreased by $60 \%, 7 \%$, and $40 \%$ respectively. Using the ATC-40 capacity spectrum method, it was possible to ascertain that the presence of the infills allowed the IF performance to increase up to $130 \%$ with respect to $\mathrm{BF}$.

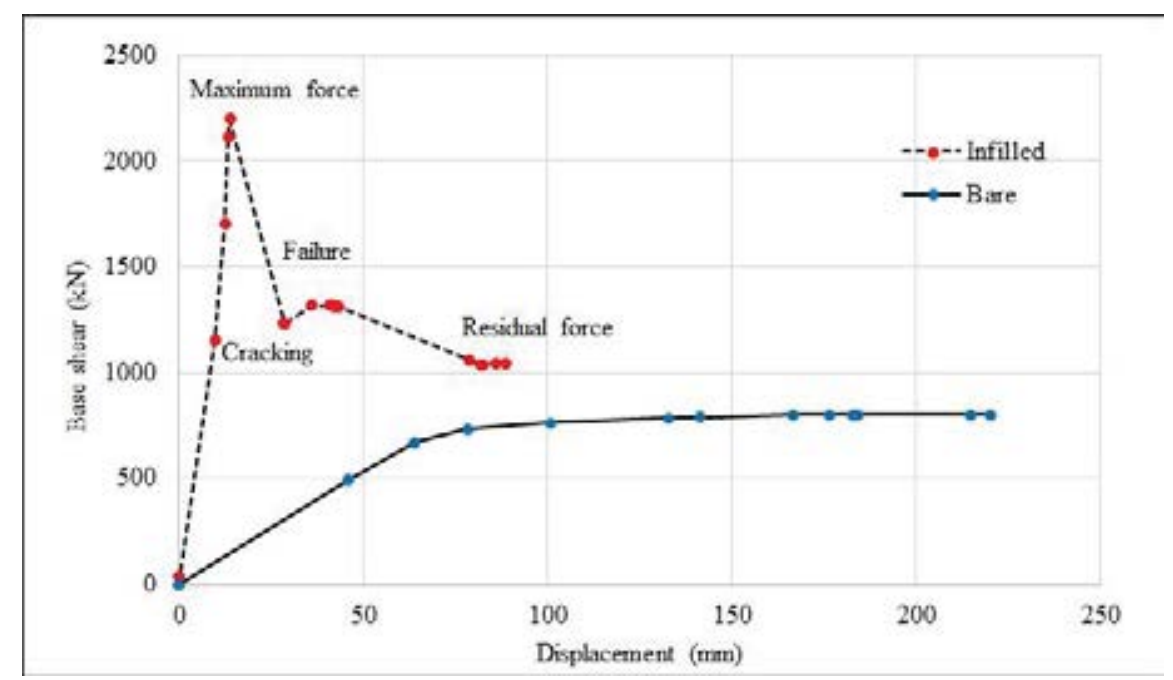

Figure 11. Capacity curves of the bare frame (solid line) and of the infilled RC frame (dashed line) 
The IF model allowed to correctly detect the presence of the most relevant in-plane failure mechanisms in the infill walls, such as, diagonal cracking, corner crushing, bed sliding/shear failure (figures 5-6). This was highlighted by the behavior of the strut elements, which got damaged in the same locations observed in the building. It was also confirmed that the infill walls stiffen the frame and thus reduce the damage in the reinforced concrete elements. Finally, as a last remark, it was confirmed that if the infill walls are made with bricks having strength higher than the mortar strength, an additional friction-related energy dissipation develops during cyclic loading, thus reducing the overall response of the structure and thus avoiding brittle failures in the bricks. This important phenomenon, which has two-fold beneficial consequences, is naturally accounted for in the proposed model through the use of the basic parameters of friction coefficient between mortar and brick surface and mortar strength

\section{CONCLUSIONS}

The following conclusions can be drawn from the study presented in this paper:

- The analysis results obtained from numerical model show good agreement with the observed in-situ failure pattern on the case study building.

- The analysis results show that the seismic performance of the selected building is correctly predicted by including an appropriate model of the infilled frame.

- In-situ observation and analysis results confirm that infill walls have strong influence on the seismic performance of building. Therefore, types of infill walls, material used and mechanical characteristics of materials are important to consider when deal with IRC frame structures, especially in Pakistan where this practice is not commonly applies.

- Strength and stiffness of the selected IRC building considerably increased with infill walls while less ductile failure is observed. Therefore, effect of infill walls should be carefully accounted for in appropriate models, both in designing new structures and in assessing existing structures.

- The proposed numerical model considers the effects of commonly ignored yet important parameters such as friction coefficient between mortar and brick surface and mortar strength, which is simple to apply and requires less computation efforts as compare to more detail models, thus, helping practitioners and structural engineer to deal with IRC structures.

\section{ACKNOWLEDGMENT}

The author acknowledged the financial supports of the Italian Agency for development cooperation (AICS) partnership for knowledge (PfK) 4 Project, the Italian ministry of foreign affairs for providing an opportunity to present the contribution reported here. The present work has been partially carried out in the framework of DPC/ReLUIS project 2019/2021.

\section{REFERENCES}

[1] N. A. Khan, C. Nuti, B. Briseghella, G. Monti, and A. V. Bergami, "State of the art and practice of masonry infilled RC frame structures subjected to in plane loading, in Pakistan, China and Europe," in First South Asia Conference on Earthquake Engineering, 2019, no. 21-22 February 2019.

[2] S. A. A. Shah, K. Shahzada, and Q. Samiullah, "Influence of Brick Masonry Infilled Wall on Seismic Performance of Reinforced Concrete Frame," NED Univ. J. Res., vol. XVII, no. 3, pp. 15-29, 2020, doi: 10.35453/nedjr-stmech-2018-0013.

[3] J. Akbar, N. Ahmad, B. Alam, and M. Ashraf, "Seismic performance of RC frames 
retrofitted with haunch technique," Struct. Eng. Mech., vol. 67, no. 1, pp. 1-8, 2018, doi: 10.12989/sem.2018.67.1.001.

[4] M. Ahmed, S. H. Lodi, S. S. Ali, and N. Alam, "Seismic Risk Assessment of Built Environment in Pakistan," 2014, vol. Second Eur, no. Aug. 25-29, 2014.

[5] W. H. Encyclopedia, "Brick masonry construction in Pakistan," 2013.

[6] A. V. Bergami and C. Nuti, "Experimental tests and global modeling of masonry infilled frames," Earthq. Struct., vol. 9, no. 2, pp. 281-303, 2015, doi: 10.12989/eas.2015.9.2.281.

[7] B. C. of P. [2007] Seismic, "Building Code of Pakistan [2007] Seismic Provisions, Ministry of Housing and Works, Islamabad, Pakistan."

[8] A. Furtado, H. Rodrigues, A. Arêde, H. Varum, M. Grubišić, and T. K. Šipoš, "Prediction of the earthquake response of a three-storey infilled RC structure," Eng. Struct., vol. 171, no. May, pp. 214-235, 2018, doi: 10.1016/j.engstruct.2018.05.054.

[9] A. Furtado and M. Teresa De Risi, "Recent Findings and Open Issues concerning the Seismic Behaviour of Masonry Infill Walls in RC Buildings," Adv. Civ. Eng., vol. 2020, 2020, doi: 10.1155/2020/9261716.

[10] H. Rodrigues, H. Varum, and A. Costa, "Simplified macro-model for infill masonry panels," J. Earthq. Eng., vol. 14, no. 3, pp. 390-416, 2010, doi: 10.1080/13632460903086044.

[11] N. A. Khan, M. F. Tahir, C. Nuti, B. Briseghella, and A. V. Bergami, "Influence of Brick Masonry Infill Walls on Seismic Response of RC Structures," Tech. Journal, UET Taxila, vol. 24, no. 3, pp. 15-23, 2019.

[12] H. Huang and H. V. Burton, "A database of test results from steel and reinforced concrete infilled frame experiments," Earthq. Spectra, vol. 36, no. 3, pp. 1525-1548, 2020, doi: $10.1177 / 8755293019899950$.

[13] D. Addessi, P. Di, C. Gatta, and E. Sacco, "Multiscale analysis of out-of-plane masonry elements using different structural models at macro and microscale," vol. 247, 2021.

[14] B. Behera and R. P. Nanda, "In-plane shear strengthening of brick masonry panel with geogrid reinforcement embedded in bed and bed-head joints mortar," vol. 227, no. February 2020, 2021.

[15] H. Huang, H. V. Burton, and S. Sattar, "Development and Utilization of a Database of Infilled Frame Experiments for Numerical Modeling," J. Struct. Eng., vol. 146, no. 6, p. 04020079, 2020, doi: 10.1061/(asce)st.1943-541x.0002608.

[16] L. Facconi and F. Minelli, "Retrofitting RC infills by a glass fiber mesh reinforced overlay and steel dowels: experimental and numerical study," Constr. Build. Mater., vol. 231, 2020, doi: 10.1016/j.conbuildmat.2019.117133.

[17] H. Huang and H. V. Burton, "Classification of in-plane failure modes for reinforced concrete frames with infills using machine learning," J. Build. Eng., vol. 25, 2019, doi: 10.1016/j.jobe.2019.100767.

[18] C. Butenweg, M. Marinković, and R. Salatić, "Experimental results of reinforced concrete frames with masonry infills under combined quasi - static in - plane and out of - plane seismic loading," Bull. Earthq. Eng., no. 0123456789, 2019, doi: 10.1007/s10518-019-00602-7.

[19] L. N. Koutas and D. A. Bournas, "Out-of-Plane Strengthening of Masonry-Infilled RC Frames with Textile-Reinforced Mortar Jackets," J. Compos. Constr., vol. 23, no. 1, p. 04018079, 2019, doi: 10.1061/(asce)cc.1943-5614.0000911.

[20] A. Furtado, H. Rodrigues, A. Arêde, and H. Varum, "Double-Leaf Infill Masonry Walls Cyclic In-Plane Behaviour: Experimental and Numerical Investigation," Open Constr. Build. Technol. J., vol. 12, no. 1, pp. 35-48, 2018, doi: 10.2174/1874836801812010035. 
[21] M. G. d'Aragona, M. Polese, M. Di Ludovico, and A. Prota, "Seismic vulnerability for RC infilled frames: Simplified evaluation for As-built and retrofitted building typologies," Buildings, vol. 8, no. 10, 2018, doi: 10.3390/buildings8100137.

[22] N. Tarque, L. Candido, G. Camata, and E. Spacone, "Masonry infilled frame structures: State-of-the-art review of numerical modelling," Earthq. Struct., vol. 8, no. 1, pp. 225251, 2015, doi: 10.12989/eas.2015.8.1.225.

[23] F. Di Trapani, L. Cavaleri, G. Bertagnoli, G. Mancini, D. Gino, and M. Malavisi, "Definition of a fiber macro-model for nonlinear analysis of infilled frames," COMPDYN 2017 - Proc. 6th Int. Conf. Comput. Methods Struct. Dyn. Earthq. Eng., vol. 2, pp. 3281-3296, 2017, doi: 10.7712/120117.5645.18525.

[24] N. Ahmad, Y. I. Badrashi, Q. Ali, H. Crowley, and R. Pinho, "Development of Displacement-Based Method for Seismic Risk Assessment of RC Building Stock of Pakistan," Proc Int. Conf. Earthq. Eng. Seismol., no. Icees, 2011.

[25] D. Combescure, F. Pires, P. Cerqeuira, and P. Pegon, "Tests on masonry infilled r/c frames and its numerical interpretation," 11th World Conference on Earthquake Engineering, Acapulco. 1996.

[26] Sacchi, M.G., and Riccioni, R., "Comportamento Statico e Sismico Delle Strutture Murarie," CLUP Ed. Milano, Italy, 1982.

[27] J. B. Mander, M. J. N. Priestley, and R. Park, "Theoretical stress-strain model for confined concrete," Struct. Eng., vol. 114, no. 8, pp. 1804-1826, 1988.

[28] A. Ahmed and K. Shahzada, "Seismic vulnerability assessment of con fi ned masonry structures by macro- modeling approach," vol. 27, no. June, pp. 639-649, 2020.

[29] M. Javed, "Seismic Risk Assessment of Unreinforced Brick Masonry Buildings System of Northern Pakistan," Engineering, p. 230, 2009. 